\title{
Transcriptome sequencing and global analysis of blue light-responsive genes provide clues for high carotenoid yields in Blakeslea trispora
}

\section{Xin Ge}

Hebei University

Ruiqing Li

Hebei University

Xiaomeng Zhang

Hebei University

Jingyi Zhao

Hebei University

Yanan Zhang

Hebei University

Qi Xin ( $\nabla$ xinqiqiqixin@163.com )

Hebei University https://orcid.org/0000-0002-3200-3500

\section{Research Article}

Keywords: Blakeslea trispora, RNA-seq analysis, blue light, carotenogenesis

Posted Date: October 18th, 2021

DOl: https://doi.org/10.21203/rs.3.rs-939133/v1

License: @ (1) This work is licensed under a Creative Commons Attribution 4.0 International License. Read Full License 


\section{Abstract}

Blakeslea trispora has great potential uses in industrial production because of the excellent capability of producing a large quantity of carotenoids. However, the mechanism of light induced carotenoid biosynthesis even the structural and regulatory genes in pathways remain unclear. In this paper, we reported the first transcriptome study in $B$. trispora in which we have carried out global survey of expression changes of genes participated in blue light response. We verified that the yield of $\beta$-carotene reaching to 3-fold when transferred from darkness to blue light for $24 \mathrm{~h}$ and the enhancement of transcription levels of carRA and $\operatorname{car} B$ presented a positive correlation with the increase in carotenoid production. RNA-seq analysis revealed that 1124 genes were upregulated and 740 genes were downregulated respectively after blue light exposure. Annotation through GO, KEGG, Swissprot and COG databases showed 11119 unigenes compared well with known gene sequences, 5514 unigenes were classified into Gene Ontology, and 4675 unigenes were involved in distinct pathways. Among the blue light responsive genes, 4 genes ( $\operatorname{carG1}$, carG3, carRA and carB) identified to function in carotenoid metabolic pathways were dominantly upregulated. We also discovered that $142 \mathrm{TF}$ genes belonging to 45 different superfamilies showed significant differential expression ( $\leq \leq 0.05), 62$ of which were obviously repressed by blue light. The detailed profile of transcription data will not only allow us to conduct further functional genomics study in $B$. trispora, but also enhance our understanding of potential metabolic pathway and regulatory network involved in light regulated carotenoid synthesis.

\section{Introduction}

Carotenoids, widely known as lycopene, astaxanthin and other terpenoid compounds. represent a group of naturally occurring pigments with red, orange or yellow color. They have a broad market demand and are used extensively as natural colorants in food for years. But more importantly, they have strong antioxidant effect and are beneficial to human health. Using microorganisms to produce carotenoids is an environmentally friendly strategy compared to traditional methods of chemical synthesis and direct extraction from plants (Foong et al. 2021; Johnson and Schroeder 1996; Mussagy et al. 2021). Blakes/ea trispora, a member of Mucorales species, is featured by the sexual phase between the plus and minus mating partners among heterothallic species. It produces zygospores during the sexual development and accumulates carotenoids within the hypha through the whole growth cycle (Lee and Idnurm 2017). The strain has great potential uses in industrial production because of the excellent capability of producing a large quantity of lycopene during sexual reproduction (Lopez-Nieto et al. 2004). It has been confirmed in $B$. trispora that lycopene cyclase that mediates lycopene cyclization and lycopene dehydrogenase that converts phytoene to lycopene encoded respectively by $\operatorname{car} R A$ and $\operatorname{car} B$ are the crucial enzymes for carotenoid biosynthesis (Breitenbach et al. 2012; Rodriguez-Saiz et al. 2004; Schmidt et al. 2005). In the past few years, researchers have identified several genes involved in mating by cDNA-AFLP, but there have little reports on the regulation mechanism of carotenoid production (Kuzina et al. 2008). In addition to sexual reproduction, light also affected carotenoids synthesis with a decrease in carotenoid production under continuous light exposure and an increase in production after dark cultured and then under light (Quiles-Rosillo et al. 2005). Conversely, the carotenoid synthesis was significant improved by continuous light exposure in Mucor circinelloides and Phycomyces blakesleeanus (Almeida and Cerda-Olmedo 2008; Quiles-Rosillo et al. 2005), indicating that there existed obviously difference in light signal reception and transduction .

Blue light is an important environmental signal for various organisms affecting their developmental and physiologic processes mediated by photoreceptors (Corrochano 2019; Fuller et al. 2015). Our knowledge about 
photoreceptors involved in these responses has been derived from different fungal species, including Neurospora crassa, Aspergillus nidulans, Fusarium fujikuroi, P. blakesleeanus, etc (Corrochano and Garre 2010; Kim et al. 2014; Purschwitz et al. 2008; Ruiz-Roldan et al. 2008). The photoreceptors identified include the White Collar proteins and cryptochromes for blue light, opsins for green light, and phytochromes for red light (He and Liu 2005; Wang et al. 2018). The best-described blue light photoreceptors in fungi are WC-1 and WC-2 which serves as the central components in the blue-light signal transduction pathway and have been reported in ascomycetes, basidiomycetes and zygomycetes (Corrochano and Garre 2010; Liu et al. 2003; Yang et al. 2016). After receiving the light signals, white collar complex (WCC) formed by WC-1 and WC-2 interaction in vivo subsequently binds to the promoters of light-regulated genes in order to rapidly activate transcription in response (Smith et al. 2010; Wang et al. 2015). The typical structure of WC proteins was slightly different. In addition to a GATA zinc-finger DNA-binding motif, WC-1 possesses three PAS domains while WC-2 usually exhibits only one PAS which is involved in the protein-protein interaction (Cheng et al. 2002). Multiple copies of WC are widespread in Mucorales species. Since P.blakesleeanus is quite sensitive to light stimulation, it has arosen great interests of researchers and was used as a model species for researching blue light signal transduction since 1969 (Bergman et al. 1973; Polaino et al. 2017). After three wc-1 and four wc-2 genes have been identified in P.blakesleeanus, Using lightresponsive blind mutants, MadA and MadB were also shown to form a WCC-like complex that plays a dominant role in all known light responses, including phototropism of the sporangiophores, activation of carotenoid synthesis, and inhibition of sexual reproduction (Sanz et al. 2009; Shakya and Idnurm 2017). However, since efficient genetic manipulation including gene knockout or overexpression towards P.blakesleeanus was not available, functional studies on WC proteins have been hampered for a long time other than MadA and MadB (Polaino et al. 2017; Tagua et al. 2020). Another blue light receptor, CryA, belonging to the cryptochrome-DASH family, has been well investigated in P. blakesleeanus, which has complete photocleavage synthase activity and can repair CPD damage on single- and double-stranded DNA (Tagua et al. 2015). Functional studies on the multicopy WC proteins were mainly carried out in $M$. circinelloides, that is another representative strain of zygomycetes, just because of the development of molecular tools to genetically manipulate this strain (Nagy et al. 2017; Navarro et al. 2013). With the help of gene knockout, the light response of the three WC-1 proteins were emerged: McWC-1a and McWC-1c were respectively involved in mediating phototropism and light-driven carotenoid synthesis, while McWC-1b regulated carotenoid production independent to light signal (Navarro et al. 2013; Silva et al. 2006). CrgA, another transcription factor regulating carotenoids synthesis, was initially discovered as a negative regulator. It was subsequently shown that carotenoids accumulated in a $\operatorname{crg} A$-deletion strain both under light and dark conditions (Lorca-Pascual et al. 2004; Silva et al. 2008). Furthermore, light enhanced the transcription level of carotenoid synthesis genes and consequently improved the carotenoids content. Homologous protein of $\mathrm{CrgA}$ in $B$. trispora was also functionally clarified through gene complement in M. circinelloides $\triangle \mathrm{crg} A$ strain as well as gene knockout in B. trispora (Luo et al. 2020; Quiles-Rosillo et al. 2005). The phenotype analysis combining the double deletion mutants of genes Mcwc-1 and $\operatorname{crg} A$ showed that CrgA negatively regulate carotenoid synthesis in a way independent of McWC-1c. Further studies showed that, as an E3 ubiquitin ligase, CrgA inhibits the transcriptional activation of carotenogenic genes by the ubiquitination modification of McWC-1b (Silva et al. 2008). Recent studies have shown that $\operatorname{crgA}$ deficiency alters intracellular metabolic flow, and the increase in carotenoid production is only part of its effect on intracellular metabolism (Luo et al. 2020).

As compared to many loss-of-function mutants obtained by physical and chemical mutagenesis methods in $P$. blakesleeanus, very few mutants of B. trispora have been reported so far (Bergman et al. 1973; Tagua et al. 
2020). More important, genetic manipulation for this multinucleate fungus is extremely difficult to achieve due to the heterokaryons would appear after the exogenous genes were transferred into any mycelia. Consequently, the study on either the mechanism of carotenogenesis in this strain or effort for genetic improvement is seriously hindered for years. It is widely accepted that RNA-seq technology appears to be the most powerful tool for transcriptome analysis and has great potential to investigate the genes involving in alteration of specific factors. The aim of the study was to decipher the transcriptome changes that take place in light response and the regulatory mechanisms of candidate genes involved in light-induced carotenoid biosynthesis. Our work for the first time provided gene expression differences between blue light and dark conditions at a whole genome level. Because the lack of stable and efficient genetic manipulation system as well as very high rates of heterokaryon formation for $B$. trispora, the results offer significant information and new research targets for investigators to further clarify gene functions in vitro.

\section{Materials And Methods}

\section{Strains, medium and growth conditions}

In this study $B$. trispora NRRL2896(-), used as the wild type strain, was cultured in PDA medium at $28^{\circ} \mathrm{C}$ for $2-4$ days to achieve mycelial growth. Sporangiospore were harvested from mycelia grown at 5th day grown on YpSs agar medium and kept in glycerol $\left(40 \% \mathrm{w} / \mathrm{v}\right.$ in water) at $-80^{\circ} \mathrm{C}$. For blue light illumination, plates inoculated with $10^{4}$ spores were previously incubated in the dark for $60 \mathrm{~h}$ and then exposed to continuous blue light at 1.34 $\mathrm{W} / \mathrm{m}^{2}$ for different times intervals. The mycelia were collected in darkness after irradiation and then frozen immediately in liquid nitrogen at the selected time points. Mycelia without blue-light illumination were also obtained in the same procedure and used for controls.

\section{Carotenes Extraction and Chemical Analyses}

Carotenes were extracted from the $B$. trispora strain grown YPD solid medium for $84 \mathrm{~h}$ in the dark and $60 \mathrm{~h}$ in the dark followed by $24 \mathrm{~h}$ under blue light. The mycelia were washed with $\mathrm{dd}_{2} \mathrm{O}$ and dried between paper towels and lyophilized. The freeze-dried mycelium powder was weighed and then suspended with 2 ml of ethyl acetate and extracted several times until the mycelium was colorless. The organic phase extracted was evaporated at 30 ${ }^{\circ} \mathrm{C}$ in a vacuum, dissolved in $500 \mu \mathrm{L}$ ethyl acetate and subjected to HPLC. For HPLC analysis, carotenoids were identified and quantified using a column Ultimate XB-C18 end capped $5 \mu \mathrm{m}, 4.6 \times 150 \mathrm{~mm}$ reverse phase column (Welch Technology, China). The eluents used were acetonitrile: methanol: dichloromethane (7:2:2, v/v). Detection of $\beta$-carotene was made at $453 \mathrm{~nm}$, which is the wavelength of maximum absorption of $\beta$-carotene. The concentrations of $\beta$-carotene were estimated at basis of an adequate standard curve using its standard compound.

\section{The extraction and purification of mRNA}

The mycelia of $B$. trispora grown in the dark and treated with blue light were harvested, frozen in liquid nitrogen, and ground. Total RNA was extracted using TransZo/Up RNA reagent (TransGen Biotech China) according to the manufacturer's instructions. The quality and integrity of total RNA was checked on Agilent Technologies 2100 Bioanalyzer (Agilent Technologies, Waldbroon, Germany).

\section{High-throughput sequencing}


For high-throughput sequencing, $3 \mu \mathrm{g}$ total RNA obtained from the three biological replicates of $B$. trispora in the dark and blue light were used as input material for the RNA-seq sample preparations. Sequencing libraries were generated using the NEBNext Ultra II RNA Library Prep Kit for Illumina (\#E7775) and then sequenced on a Novaseq platform (Illumina) by Shanghai Personal Biotechnology Cp. Ltd.

\section{Data Analysis}

The Illumina Hiseq 2000 system was used to sequence approximately 242 million 150 bp paired-end reads. These sequences were quality-filtered and mapped to the $B$. trispora F921 v1.0 reference genome, available from the JGI Genome Portal (https://mycocosm.jgi.doe.gov/Blatri_F921_1/Blatri_F921_1.home.html). The genes were annotated using $B$. trispora F921 v1.0 reference genome. For the differential expression analysis, using two-fold change cutoff, that is, log 2 fold change $\geq 1$ or $\leq-1$ and an adjusted P-value $\leq 0.05$ as thresholds. Functional enrichment analysis of differentially expressed genes, GO terms significantly enriched (that is, with P-values 50.05), and KEGG analysis were based on the integrated cloud platform of I-Sanger (https://www.i-sanger.com/).

\section{Reverse transcription fluorescence quantitative PCR}

The mycelia for real-time PCR were prepared same as mycelia for RNA-sequencing. RNA extraction was performed as previously reported. Total RNA was treated with DNase\to remove gDNA. cDNA was subsequently synthesized using Takara PrimeSript first strand c-DNA synthesis kit (EasyScript ${ }^{\circ}$ First-Strand cDNA Synthesis SuperMix, Beijing, China) according to the manufacturer's instructions. To validate the differentially expressed genes, 12 genes were randomly selected and the primers used were described in Table S1. Quantitative real-time PCRs were performed using SYBR green supermix (TransStart® Top Green qPCR SuperMix Takara, TransStart ${ }^{\circledR}$ Top Green qPCR SuperMix) on a LightCycler instrument (Roche). Reactions were performed in triplicates with a total volume of $20 \mu \mathrm{L}$, including $250 \mathrm{nmol} / \mathrm{L}$ forward primer, $250 \mathrm{nmol} / \mathrm{L}$ reverse primers and $2 \mu \mathrm{L} \mathrm{cDNA}$ template (10-fold diluted). The amplification program used in this study consisted of: $95^{\circ} \mathrm{C}$ for 3 minutes; 40 cycles of $95^{\circ} \mathrm{C}$ for 10 seconds and $60^{\circ} \mathrm{C}$ for 20 seconds; and melting curve of $60^{\circ} \mathrm{C}$ to $95^{\circ} \mathrm{C}$ at increments of $0.5^{\circ} \mathrm{C}$ for 10 seconds. The GAPDH gene was used as the endogenous control to normalize the total amount of cDNA present in each sample. Then, the results obtained from light stimulation mycelia were normalized to the results of mycelia grown in the dark. Data analysis from three biological for each gene was performed using the comparative CT method $(\triangle \Delta C T)$.

\section{Results}

\section{The response to blue light and transcription of key genes of carotenoid synthesis}

The phenomenon of the photoresponse in $M$. circinelloides has been initially discovered several years ago and their gene involvement in the biological process has also been studied (Corrochano and Garre 2010). In order to study the effect of blue light on carotenoid synthesis of $B$. trispora, we examined the vegetative growth on solid media under dark condition and blue light irradiation. To our expected, although little difference could be seen in mycelial growth, the hypha appears white-yellowish color after 24 hours inoculation due to the production of small amounts of $\beta$-carotene in the dark, while it becomes deep yellow with the increasing blue light exposure time because of the rapid accumulation of $\beta$-carotene triggered by blue light (Fig. 1a). To confirm that color 
differences are closely related to the level of carotenoid synthesis, we therefore determined the content of $\beta$ carotene in cells by high performance liquid chromatography. Compared to that in the hyphae kept in a dark environment, the yield of $\beta$-carotene reached to double-triple times after blue-light irradiation for 24 hours (Fig. 1b). In summary, blue light indeed contributes to accelerate carotenoid synthesis of $B$. trispora.

To further investigate the potential molecular mechanism on carotenogenesis after blue light stimulation in $B$. trispora, the transcription levels of $\operatorname{carRA}$ and $c a r B$, the key genes in the carotenoid synthesis pathway, were examined at different time point within 30 minutes after blue light irradiation. The result shows the transcription levels of the two genes are up-regulated about 15- and 40-fold respectively, which is consistent with the conspicuous increase in carotenoid production. It suggested that blue light regulates the transcription of the related genes in the carotenoid biosynthesis pathway of $B$. trispora directly or indirectly (data not shown) and could be attributed to up-regulation of the genes encoding carotenoid metabolic pathway enzymes

In order to study the time courses transcriptional response of these two genes after a prolonged exposure to blue light, and to select a optimum time point for subsequent RNA-seq assay, total RNA was isolated from mycelia irradiated with blue light for a period of up to $60 \mathrm{~min}$ and the induced transcriptional curves of $\operatorname{car} B$ and $\operatorname{car} R A$ were shown in Fig. 1c. The transcripts accumulation of both genes increased rapidly after blue light illumination. Interestingly, the maximum accumulation for $c a r B$ reached to 80 -fold within 10 minutes after irradiation and there existed two peaks in the transcription curve of carRA at time points of 8 minutes and 30 minutes. The transcription levels of both genes returned to near basal levels after $60 \mathrm{~min}$. This result is also consistent with previous reports of $M$. circinelloides.

\section{Analysis of genes differentially expressed under light and dark conditions}

To investigate the role of blue light in the global transcriptome of B.trispora, we performed transcriptome analyses of mycelia using RNA-seq under dark and blue light conditions. The mycelia of B.trispora were collected when exposed to 10 minutes of blue light after $48 \mathrm{~h}$ of growth in the dark. Samples from three biological replicates of each condition were sequenced and resulted in approximately 242 million 150 bp paired-end reads, corresponding to $31 \mathrm{GBs}$ of nucleotides (Table S2). There was a high Pearson correlation $\left(R^{2} \geq 0.98\right)$ between the three biological replicates of each condition. Differential expression analysis was performed between blue light and darkness conditions and 1864 modulated genes were identified, using a $p \leq 0.05$ as the threshold. Among these genes, 1124 were upregulated and 740 were downregulated, applying a two-fold change (that is, log2 fold change $\triangle \geq 1$ ) and an FDR $\leq 0.05$ as the threshold (Fig. 2a). To verify that our RNA-Seq data is reliable, carRA, carB and 10 other genes modulated by blue light were randomly chosen for RT-qPCR analysis. Of these genes, 8 were upregulated and 4 were downregulated (Table S3). The significant Pearson correlation $\left(\mathrm{R}^{2}=\right.$ 0.9096) of the log2 fold change of gene expression was demonstrated when comparing the data obtained by RNA sequencing and real-time PCR, which suggested that gene expression levels from the former were confirmed by the latter and the RNA-seq analysis is high in reliability (Fig. 2b).

\section{Enrichment Analysis Of Go And Kegg}

The functional categorization of the different expression genes was analyzed using the terms of GeneOntology (GO). The 1864 differentially expressed genes (DEGs) were partitioned into 41 functional group categories under three major categories: "cellular component", "biological process" and "molecular function" (Fig. 3a). These major 
categories sorted into several subcategories and 5, 25, and $62 \mathrm{GO}$ terms for the three categories respectively appeared enrichment based on $p \leq 0.05$. The most 20 enriched terms in these categories were shown in Fig. $3 a$. Within the biological process category, 14 terms, including "regulation of nucleobase-containing compound metabolic process" (GO:0019219), "regulation of transcription" (GO:0006355), "regulation of RNA metabolic process" (G0:0051252) and other processes involved in the regulation of gene expression (G0:1903506, GO:2001141, GO:0009889, G0:0010556, GO:0031326, G0:2000112, G0:0005975, G0:0010468, GO:0006351, GO:0097659 and G0:0032774) were the most representative. For the molecular function category, "DNA-binding transcription factor activity" (GO:0003700), "transcription regulator activity" (G0:0140110), "secondary active transmembrane transporter activity" (G0:0015291), "molecular transducer activity" (G0:0060089) and "sequencespecific DNA binding" (GO:0043565) were predominantly represented. And for the cellular components category, GO term "membrane" (G0:0016020) was significantly enriched (Fig. 3b).

To investigate metabolic pathways involved in the response to blue light, DEGs were subjected to KEGG pathways enrichment analysis (Fig. 4). However, since there was no pathway information available about this strain in the KEGG database, we analysis the metabolic pathways of DEGs using the reference genome from JGI. Up to 4640 DEGs could be annotated, and 2826 pathways were obtained. Most of the DEGs involved in the "Metabolism of Complex Lipids" (35 genes), "Metabolism of Complex Carbohydrates" (55 genes), "Carbohydrate Metabolism" (50 genes), "Amino Acid Metabolism" (47 genes), and "Metabolism of Cofactors and Vitamins" (22 genes). The top 20 enriched pathways were listed in Fig. 4. Considering $p \leq 0.05$ as the threshold, only six pathways were significantly enriched, including "Aminosugars metabolism," "Fluorene degradation," "starch and sucrose metabolism," "Ascorbate and aldarate metabolism," "Cyanoamino acid metabolism" and "Glycerolipid metabolism". These enriched pathways provide us a direction to further investigate the metabolic processes and gene functions which participated in the blue light response in B.trispora.

\section{The Identification Of Genes Involved In Blue Light Response}

After a comprehensive overview of the transcriptome data, the top 20 upregulated genes with more than $2^{7}$ fold increase in mRNA level and the top 10 downregulated genes with a $2^{3.5}$ to $2^{7.7}$ fold reduction in transcriptional level were selected to simplify the analysis (Table 1). The KOG description and KOG class about these genes were also listed in the table. The top 20 upregulated genes included four related to energy production and conversion (ID 529211, 542283, 373722 and 500322). A gene which encodes a deoxyribodipyrimidine photolyase (ID 383338) was predicted as the homologue of cryptochrome-DASH in P. blakesleeanus. The 4-dihydrotrisporin dehydrogenase (ID 527621), which participate in trisporic acid synesis pathway is up-regulated by $2^{9.2}$. Genes that encode cytochrome P450 (ID 398086), E3 ubiquitin ligase (ID 497534), velvet factor (ID 530917), one protein containing FAS1 domain (ID 452672), one gluconate transport-inducing protein (ID 464910), one amino acid transporter (ID 420874) and one HMG box-containing protein (ID 481629) were also upregulated, as well as seven unknown proteins (ID 530917, 392850, 489762, 469733, 499226, 396672, and 525646). Among the downregulated genes, 7 proteins are associated with transport and metabolism, of which four involving in amino acid transport and metabolism (ID 416571, 566594, 430881 and 528068), two involving in lipid transport and metabolism (ID 417993 and 465246), and one involving in carbohydrate transport and metabolism (ID 457478). One protein participating in cell cycle control (ID 461298) and one putative protein phosphatase participating in posttranslational modification (ID 491548) were also annotated. Besides that, the functions of 11 proteins (ID 360254, 379721, 459644, 388849, 465314, 391569, 540410, 542974, 407061, 377374 and 484741) were still not 
clarified. Nearly half of these 40 significantly DEGs with significant transcript levels encoded for unknown proteins, which provided us with many breakthroughs to study the mechanism of light response. 
Table 1

Log2 fold change (FC) of the top 20 differentially expressed genes in B.trispora after blue light exposure.

\begin{tabular}{|c|c|c|c|c|c|}
\hline & $\begin{array}{l}\text { Protein } \\
\text { ID }\end{array}$ & KOG description & KOG class & $\begin{array}{l}\text { Annotation } \\
\text { Description }\end{array}$ & $\log _{2} F C$ \\
\hline \multirow[t]{16}{*}{ Up } & 398086 & $\begin{array}{l}\text { Cytochrome P450 } \\
\text { CYP4/CYP19/CYP26 } \\
\text { subfamilies }\end{array}$ & $\begin{array}{l}\text { Lipid transport and } \\
\text { metabolism }\end{array}$ & $\begin{array}{l}\text { cytochrome P-450 } \\
\text { cyp509A1 }\end{array}$ & 12.379 \\
\hline & 497534 & $\begin{array}{l}\text { Predicted E3 ubiquitin } \\
\text { ligase }\end{array}$ & $\begin{array}{l}\text { Posttranslational } \\
\text { modification, protein } \\
\text { turnover, chaperones }\end{array}$ & $\begin{array}{l}\text { PUA-like domain- } \\
\text { containing protein }\end{array}$ & 12.004 \\
\hline & 529211 & $\begin{array}{l}\text { NADH:flavin } \\
\text { oxidoreductase/12- } \\
\text { oxophytodienoate } \\
\text { reductase }\end{array}$ & $\begin{array}{l}\text { Energy production and } \\
\text { conversion }\end{array}$ & $\begin{array}{l}\text { hypothetical } \\
\text { protein }\end{array}$ & 11.038 \\
\hline & 383338 & $\begin{array}{l}\text { Deoxyribodipyrimidine } \\
\text { photolyase/cryptochrome }\end{array}$ & $\begin{array}{l}\text { Replication, } \\
\text { recombination and repair }\end{array}$ & $\begin{array}{l}\text { DNA photolyase } \\
\text { /Cryptochrome }\end{array}$ & 10.87 \\
\hline & 452672 & $\begin{array}{l}\text { Fasciclin and related } \\
\text { adhesion glycoproteins }\end{array}$ & $\begin{array}{l}\text { Cell } \\
\text { wall/membrane/envelope } \\
\text { biogenesis }\end{array}$ & $\begin{array}{l}\text { FAS1 domain- } \\
\text { containing protein }\end{array}$ & 10.414 \\
\hline & 530917 & hypothetical protein & Unknown & $\begin{array}{l}\text { Velvet factor- } \\
\text { domain containing } \\
\text { protein }\end{array}$ & 9.834 \\
\hline & 481629 & $\begin{array}{l}\text { HMG box-containing } \\
\text { protein }\end{array}$ & $\begin{array}{l}\text { General function } \\
\text { prediction only }\end{array}$ & expressed protein & 9.587 \\
\hline & 527621 & $\begin{array}{l}\text { Predicted short chain- } \\
\text { type dehydrogenase }\end{array}$ & $\begin{array}{l}\text { General function } \\
\text { prediction only }\end{array}$ & $\begin{array}{l}\text { 4-dihydrotrisporin } \\
\text { dehydrogenase }\end{array}$ & 9.245 \\
\hline & 542283 & $\begin{array}{l}\text { Zinc-binding } \\
\text { oxidoreductase }\end{array}$ & $\begin{array}{l}\text { Energy production and } \\
\text { conversion }\end{array}$ & $\begin{array}{l}\text { hypothetical } \\
\text { protein }\end{array}$ & 9.004 \\
\hline & 464910 & $\begin{array}{l}\text { Gluconate transport- } \\
\text { inducing protein }\end{array}$ & $\begin{array}{l}\text { Carbohydrate transport } \\
\text { and metabolism }\end{array}$ & $\begin{array}{l}\text { hypothetical } \\
\text { protein }\end{array}$ & 8.595 \\
\hline & 392850 & hypothetical protein & Unknown & $\begin{array}{l}\text { hypothetical } \\
\text { protein }\end{array}$ & 7.786 \\
\hline & 489762 & hypothetical protein & Unknown & $\begin{array}{l}\text { hypothetical } \\
\text { protein }\end{array}$ & 7.546 \\
\hline & 469733 & hypothetical protein & Unknown & $\begin{array}{l}\text { hypothetical } \\
\text { protein }\end{array}$ & 7.193 \\
\hline & 552594 & GDSL lipase/esterase & $\begin{array}{l}\text { hydrolase activity, acting } \\
\text { on ester bonds }\end{array}$ & $\begin{array}{l}\text { GDSL } \\
\text { lipase/esterase }\end{array}$ & 7.145 \\
\hline & 499226 & hypothetical protein & Unknown & expressed protein & 7.107 \\
\hline & 420874 & Amino acid transporters & $\begin{array}{l}\text { Amino acid transport and } \\
\text { metabolism }\end{array}$ & $\begin{array}{l}\text { Transmembrane } \\
\text { amino acid } \\
\text { transporter protein- } \\
\text { domain containing } \\
\text { protein }\end{array}$ & 7.083 \\
\hline
\end{tabular}




\begin{tabular}{|c|c|c|c|c|c|}
\hline & $\begin{array}{l}\text { Protein } \\
\text { ID }\end{array}$ & KOG description & KOG class & $\begin{array}{l}\text { Annotation } \\
\text { Description }\end{array}$ & $\log _{2} \mathrm{FC}$ \\
\hline & 373722 & $\begin{array}{l}\text { Kynurenine 3- } \\
\text { monooxygenase and } \\
\text { related flavoprotein } \\
\text { monooxygenases }\end{array}$ & $\begin{array}{l}\text { Energy production and } \\
\text { conversion }\end{array}$ & $\begin{array}{l}\text { hypothetical } \\
\text { protein }\end{array}$ & 6.929 \\
\hline & 500322 & $\begin{array}{l}\text { Mitochondrial carrier } \\
\text { protein CGI-69 }\end{array}$ & $\begin{array}{l}\text { Energy production and } \\
\text { conversion }\end{array}$ & $\begin{array}{l}\text { Mitochondrial } \\
\text { carrier domain- } \\
\text { containing protein }\end{array}$ & 6.893 \\
\hline & 396672 & hypothetical protein & Unknown & expressed protein & 6.592 \\
\hline & 525646 & hypothetical protein & Unknown & expressed protein & 6.535 \\
\hline \multirow[t]{12}{*}{ Down } & 417993 & Predicted lipase & $\begin{array}{l}\text { Lipid transport and } \\
\text { metabolism }\end{array}$ & lipase & -5.759 \\
\hline & 360245 & hypothetical protein & Unknown & $\begin{array}{l}\text { hypothetical } \\
\text { protein }\end{array}$ & -5.476 \\
\hline & 379721 & hypothetical protein & Unknown & $\begin{array}{l}\text { hypothetical } \\
\text { protein }\end{array}$ & -4.928 \\
\hline & 416571 & Amino acid transporters & $\begin{array}{l}\text { Amino acid transport and } \\
\text { metabolism }\end{array}$ & $\begin{array}{l}\text { Transmembrane } \\
\text { amino acid } \\
\text { transporter protein- } \\
\text { domain containing } \\
\text { protein }\end{array}$ & -4.926 \\
\hline & 566594 & Amino acid transporters & $\begin{array}{l}\text { Amino acid transport and } \\
\text { metabolism }\end{array}$ & $\begin{array}{l}\text { Amino acid } \\
\text { permease-domain } \\
\text { containing protein }\end{array}$ & -4.876 \\
\hline & 459644 & hypothetical protein & Unknown & expressed protein & -4.861 \\
\hline & 465246 & Predicted lipase & $\begin{array}{l}\text { Lipid transport and } \\
\text { metabolism }\end{array}$ & lipase & -4.67 \\
\hline & 388849 & hypothetical protein & Unknown & $\begin{array}{l}\text { hypothetical } \\
\text { protein }\end{array}$ & -4.59 \\
\hline & 465314 & hypothetical protein & Unknown & $\begin{array}{l}\text { GPR1/FUN34/yaaH } \\
\text { family-domain } \\
\text { containing protein }\end{array}$ & -4.571 \\
\hline & 391569 & hypothetical protein & Unknown & $\begin{array}{l}\text { hypothetical } \\
\text { protein }\end{array}$ & -4.471 \\
\hline & 457478 & $\begin{array}{l}\text { Permease of the major } \\
\text { facilitator superfamily }\end{array}$ & $\begin{array}{l}\text { Carbohydrate transport } \\
\text { and metabolism }\end{array}$ & $\begin{array}{l}\text { Major facilitator } \\
\text { superfamily } \\
\text { domain-containing } \\
\text { protein }\end{array}$ & -4.437 \\
\hline & 540410 & hypothetical protein & Unknown & $\begin{array}{l}\text { hypothetical } \\
\text { protein }\end{array}$ & -4.432 \\
\hline
\end{tabular}




\begin{tabular}{|c|c|c|c|c|}
\hline $\begin{array}{l}\text { Protein } \\
\text { ID }\end{array}$ & KOG description & KOG class & $\begin{array}{l}\text { Annotation } \\
\text { Description }\end{array}$ & $\log _{2} \mathrm{FC}$ \\
\hline 430881 & Amino acid transporters & $\begin{array}{l}\text { Amino acid transport and } \\
\text { metabolism }\end{array}$ & $\begin{array}{l}\text { Transmembrane } \\
\text { amino acid } \\
\text { transporter protein- } \\
\text { domain containing } \\
\text { protein }\end{array}$ & -4.416 \\
\hline 542974 & hypothetical protein & Unknown & $\begin{array}{l}\text { hypothetical } \\
\text { protein }\end{array}$ & -4.358 \\
\hline 461298 & $\begin{array}{l}\text { Putative transcriptional } \\
\text { repressor regulating } \\
\mathrm{G} 2 / \mathrm{M} \text { transition }\end{array}$ & $\begin{array}{l}\text { Cell cycle control, cell } \\
\text { division, chromosome } \\
\text { partitioning }\end{array}$ & $\begin{array}{l}\text { hypothetical } \\
\text { protein }\end{array}$ & -4.355 \\
\hline 407061 & hypothetical protein & Unknown & expressed protein & -4.349 \\
\hline 377374 & hypothetical protein & Unknown & expressed protein & -4.31 \\
\hline 491548 & $\begin{array}{l}\text { Protein phosphatase, } \\
\text { regulatory subunit } \\
\text { PPP1R3C/D }\end{array}$ & $\begin{array}{l}\text { Posttranslational } \\
\text { modification, protein } \\
\text { turnover, chaperones }\end{array}$ & $\begin{array}{l}\text { Putative } \\
\text { phosphatase } \\
\text { regulatory subunit- } \\
\text { domain containing } \\
\text { protein }\end{array}$ & -4.269 \\
\hline 484741 & hypothetical protein & Unknown & expressed protein & -4.239 \\
\hline 528068 & $\begin{array}{l}\text { H+/oligopeptide } \\
\text { symporter }\end{array}$ & $\begin{array}{l}\text { Amino acid transport and } \\
\text { metabolism }\end{array}$ & $\begin{array}{l}\text { POT family-domain } \\
\text { containing protein }\end{array}$ & -4.097 \\
\hline
\end{tabular}

\section{Transcriptional level analysis of genes related to carotenoid metabolic pathways}

Light-induced carotenogenesis is a representative characterization of light responses in B.trispora. As the metabolic pathways shown (Fig. 5a), 3-hydroxy-3-methylglutaryl CoA (HMG-CoA) is reducing to mevalonate by HMG-CoA reductase and the Mucorales use MVA pathway for the synthesis of the precursors of all terpenoids, including lycopene, $\beta$-carotene, ubiquinone and squalene, in which $\beta$-carotene is catabolized to trisporic acid $C$. Some genes of this pathway have been identified and the detailed quantifications of light-dependent mRNA accumulation of these genes in B.trispora were analyzed (Fig. 5b ). The transcriptional levels of carRA and carB appear a significant increase, similar to the previous result shown in Fig. 2, whereas that of genes in the mevalonate pathway, the carotenoid catabolism and the two metabolic flux has no obvious change. The coding sequences of CarRA and CarB are separated by 611 base pairs and divergently transcribed, therefore we hypothesize that one or more unknown specific transcriptional regulators bind to the bidirectional promoter to regulate photo-carotenogenesis directly. It is worth mentioning that we identified four different GGPP synthetase genes ( $c a r G)$,of which only ID 402428 has been cloned and functional expressed. Transcriptome data indicate that there was no significant change for ID 402428 and ID 494297 in transcription level under blue light stimulation, while ID473880 and ID509961 with varying degrees of upregulation. The GGPP synthases (GGPPS) in plants have been shown to play an important role in allocating metabolic fluxes and regulating diterpenoid synthesis. Generally, more than one GGPP synthetase were discovered in plant genomes with distinct the subcellular localization. Therefore, it is important to dissect the species-specific and spatio-temporal expression as well as the subcellular localization and molecular interaction of these GGPPS for understanding metabolic regulation and genetic engineering improvement of terpenoid metabolism. 


\section{Changes In Transcription Level Of Putative Transcription Factors}

Transcription factors (TFs) are key DNA binding proteins involved in the regulation of genes expression of different signaling pathways, and the expression of stress-induced genes is mainly regulated by sequencespecific binding TFs. To identify TFs potentially involved in light response by analyzing differentially expressed mRNAs will enable us to unveil the light response mechanism, including the regulatory mechanisms of lightinduced carotenogenesis. To date, $692 \mathrm{TFs}$ were found in the genome of B.trispora (information based on the number of B.trispora transcription factors annotated in the genome portal http://genome. jgi-psf.org/ Blatri1/Blatri1.home.html), with few have already been characterized and described. $142 \mathrm{TF}$ genes belonging to 45 different superfamilies showed significant differential expression ( $p \leq 0.05), 62$ of which were repressed by blue light (Table S4). The most expressed gene encoding C3HC4-type RING finger protein (ID Bt_497534) was almost 4000 times $\left(\log _{2} \mathrm{FC}=12.004\right)$ more heavily in the blue light condition compared to in the dark. A HMG-box protein (ID Bt_497534, $\log _{2} \mathrm{FC}=9.586$ ) and another C3HC4-type RING finger protein (ID 184178, $\log _{2} \mathrm{FC}=5.825$ ) rank second and third among the regulatory proteins. The HMG-box protein also has a SAM domain which plays a role in MAPK signaling pathway and probably helps the cell respond to external light stimuli. It is noteworthy that a GATA-type TF (ID Bt_511752) with a PAS domain, which was 16 times more heavily expressed, were predicted to be an homologous of the WC-1c protein in M.circinelloides. It suggested the white collar complex (WCC) in the classical light-responsive study is also present in B.trispora and the WC-2 protein of the complex in this strain needs to be further identified. The study of TFs interactions and their integration with metabolic network under a given condition will provide us new insights into the global gene expression regulation of light response.

\section{Discussion}

B.trispora is known to be the most effective native producer of carotenoids especially lycopene and $\beta$-carotene (Rodriguez-Saiz et al. 2004). Although the putative genes involved in this biosynthesis pathway have been identified for a long time, the lack of detailed genomic information and the unavailability of genetic manipulation towards the strain were the major obstacles to further study the function of the genes as well the metabolic pathway (Ge et al. 2021; Kuzina et al. 2008). Previous studies have also revealed that both pheromones (known as trisporic acid) and blue light irradiation could strongly activate carotenoid biosynthesis, but the exact mechanism still remains unclear (Modi 1977; Quiles-Rosillo et al. 2005). With the whole genome sequences of B.trispora available, it becomes possible to screen out the specific genes which were most likely to participated in the light response mechanism based on the extensive analysis of transcriptome sequencing results under two or more conditions.

The carotenoid synthesis pathway in B.trispora is a sequential reaction process originated from acetyl CoA, during which changes in gene transcription and in the enzymatic activity caused by post-translational modification may thus affect the synthesis of $\beta$-carotene(Breitenbach et al. 2012). The currently identified regulatory proteins involved in carotenoid synthesis, including BtCrgA and multi-WC-like proteins, are closely related to light regulation (Ge et al. 2021; Luo et al. 2020). CrgA in B. trispora is proved to be a negative regulatory protein in the process of light-induced carotenoid synthesis. Previous studies have shown that $\operatorname{crgA}$ gene is upregulated after blue light irradiation compared to dark condition (Quiles-Rosillo et al. 2005). RNA sequencing analysis indicated that the transcription level of BtCrgA (ID 559549) was increased by 4.53 times, which is 
consistent with previous reports (Quiles-Rosillo et al. 2005). In M. circinelloides, CrgA, played as an E3 ubiquitin ligase, inhibits photo-induced $\beta$-carotene synthesis by a proteolysis independent ubiquitylation, and McWC-1a directly regulates the transcription level of carotenoid synthesis genes through the deactivation of McWC-1b caused by the modification (Silva et al. 2008). Based on current data, it is still under investigation that how CrgA accepted and transmitted signals cooperatively with other light response factors. In addition, CrgA is a member of the undefined protein family which shares the character of two RING finger zinc-binding domains near the Nterminus followed by a LON domain. In general, proteins containing RING finger domains belong to the E3ubiquitin ligase family, the role of which in plant photoresponse pathways has been extensively investigated (Morreale and Walden 2016). For example, the ring-finger E3 ubiquitin ligase COP1/SPA and PUB13 regulate the flowering and photomorphogenesis of Arabidopsis through direct or indirect effects on the stability of photoreceptors (Podolec and Ulm 2018; Ponnu 2020). Additionally, several E3 ubiquitin ligases named SINAT5, COP1, HOS1, ZTK, LKP2 and FKF1 are diversely involved in the photoperiodic rhythm regulation of flowering in Arabidopsis (Zoltowski and Imaizumi 2014). In B. trispora, three predicted E3 ubiquitin ligases besides CrgA have been identified (Table S4) which are all equipped with RING FINGER domain and N-terminal LON domain. The regulatory mechanism of E3 ubiquitin ligase participating in light response in plant will paving the way for clarifying the function of corresponding genes.

A detail examination on the differentially expressed genes by bioinformatics analysis, we found a locus of interest in the genome of B. trispora, Bt_383338 (predicted as deoxyribodipyrimidine photolyase/cryptochrome), the transcription level of which was increased by $2^{10.87}$ times. Moreover, we found that this protein was also a functional homolog of Cry-DASH in $P$. blakesleeanus based on multiple sequence alignment analysis. In $P$. blakesleeanus, Cry-DASH played the role of photocleavage synthase and the transcriptional activation depended on the formation of WCC complex. However, there is no experimental evidence till now that Cry-DASH as well as homologous protein functioned as photoreceptors in light signal transduction (Tagua et al. 2015). In Fusarium Fujikuroi, the mechanism that cryptochrome CryD, WcoA (homologous protein of WC-1) and VVD cooperatively regulated light-induced carotenoid synthesis was clearly clarified for the first time by means of the mature and stable genetic manipulation (Castrillo and Avalos 2015). Although $B$. trispora is phylogenetically close to $P$. blakesleeanus and the function of Cry-DASH is supposed to be conserved during the early stage of the evolution of fungi, we cannot rule out the possibility that Cry-DASH has acted as a photoreceptor in B. trispora. In addition to this, we also noticed in genome information that protein Bt_530917 in B. trispore was described as a velvet factor, which has been extensively studied in ascomycetes and basidiomycetes, but reported only in $P$. blakesleeanus among Zygomycete fungi (Tagua et al. 2020). VelB in A. nidulans regulated fungal development and secondary metabolism by forming complexes with other velvet proteins, which were influenced by environmental signaling factors such as light and temperature (Bayram and Braus 2012). Light on one hand inhibited the formation of fruited bodies during sexual reproductive process by reducing the number of VelB-VeA dimers in the nucleus, on the other hand, it also suppressed the formation of heterodimers of VelB and VosA, thus removing their inhibition to asexual development (Sarikaya Bayram et al. 2010). It has been proved that the sexual reproduction of Mucorales fungi was also inhibited under light conditions (Shakya and Idnurm 2017). Since most of these Mucorales species show heterothallism and zygospores were generated by close contact between positive and negative strains, it is necessary to hold a mating type locus ( $\operatorname{sex} P$ and $\operatorname{sex} M$ ) to regulate the production of pheromones between complementary mating partners during the stage of sexual reproduction. However, different to the fact that LaeA in $A$. nidulans inhibited the expression of velB, the transcription level of $B t$ 530917 was greatly increased. Since there was no evidence before that LaeA homologues exist in the order

Page $13 / 23$ 
Mucorales, we here identified the velvet protein suggesting that the light effect on sexual reproduction may be more complex.

\section{Declarations}

Authors' contributions Xin Ge and Qi Xin performed research, analyzed data, and wrote the paper. Ruiqing Li performed transcriptional analysis. Jingyi Zhao prepared and maintained the fungal culture. Xiaomeng Zhang and Yanan Zhang performed PCR and analyzed data. All authors reviewed and corrected the manuscript.

Acknowledgments This research has been funded by Foundation of Hebei Educational Committee (Grant No. BJ2016008), the National Natural Science Foundation of China (Grant No. 31601015) and Laboratory Open Project Program of Hebei University (Grant No. sy202019).

Availability of data and material Please contact author for data requests.

Conflict of interest Xin Ge, Ruiqing Li, Xiaomeng Zhang, Jingyi Zhao, Yanan Zhang and Qi Xin declare that they have no conflict of interest.

Code availability Not applicable.

Ethics approval Not applicable.

Consent to participate Not applicable.

Consent for publication Not applicable.

\section{References}

Almeida ER, Cerda-Olmedo E (2008) Gene expression in the regulation of carotene biosynthesis in Phycomyces. Curr Genet 53:129-137. doi:10.1007/s00294-007-0170-x

Bayram O, Braus GH (2012) Coordination of secondary metabolism and development in fungi: the velvet family of regulatory proteins. FEMS Microbiol Rev 36:1-24. doi:10.1111/j.1574-6976.2011.00285.x

Bergman K, Eslava AP, Cerda-Olmedo E (1973) Mutants of Phycomyces with abnormal phototropism. Mol Gen Genet 123:1-16. doi:10.1007/BF00282984

Breitenbach J, Fraser PD, Sandmann G (2012) Carotenoid synthesis and phytoene synthase activity during mating of Blakeslea trispora. Phytochemistry 76:40-45. doi:10.1016/j.phytochem.2011.12.017

Castrillo M, Avalos J (2015) The flavoproteins CryD and VvdA cooperate with the white collar protein WcoA in the control of photocarotenogenesis in Fusarium fujikuroi. PLoS One 10:e0119785.

doi:10.1371/journal.pone.0119785

Cheng P, Yang Y, Gardner KH, Liu Y (2002) PAS domain-mediated WC-1/WC-2 interaction is essential for maintaining the steady-state level of WC-1 and the function of both proteins in circadian clock and light responses of Neurospora. Mol Cell Biol 22:517-524. doi:10.1128/MCB.22.2.517-524.2002 
Corrochano LM (2019) Light in the Fungal World: From Photoreception to Gene Transcription and Beyond. Annu Rev Genet 53:149-170. doi:10.1146/annurev-genet-120417-031415

Corrochano LM, Garre V (2010) Photobiology in the Zygomycota: multiple photoreceptor genes for complex responses to light. Fungal Genet Biol 47:893-899. doi:10.1016/j.fgb.2010.04.007

Foong LC, Loh CWL, Ng HS, Lan JC (2021) Recent development in the production strategies of microbial carotenoids. World J Microbiol Biotechnol 37:12. doi:10.1007/s11274-020-02967-3

Fuller KK, Loros JJ, Dunlap JC (2015) Fungal photobiology: visible light as a signal for stress, space and time. Curr Genet 61:275-288. doi:10.1007/s00294-014-0451-0

Ge X, Yuan Y, Li R, Zhang X, Xin Q (2021) Structure prediction and function characterization of WC-2 proteins in Blakeslea trispora. Int Microbiol 24:427-439. doi:10.1007/s10123-021-00181-1

He Q, Liu Y (2005) Molecular mechanism of light responses in Neurospora: from light-induced transcription to photoadaptation. Genes Dev 19:2888-2899. doi:10.1101/gad.1369605

Johnson EA, Schroeder WA (1996) Microbial carotenoids. Adv Biochem Eng Biotechnol 53:119-178. doi:10.1007/BFb0102327

Kim H, Son H, Lee YW (2014) Effects of light on secondary metabolism and fungal development of Fusarium graminearum. J Appl Microbiol 116:380-389. doi:10.1111/jam.12381

Kuzina V, Ramirez-Medina H, Visser H, van Ooyen AJ, Cerda-Olmedo E, van den Berg JA (2008) Genes involved in carotene synthesis and mating in Blakeslea trispora. Curr Genet 54:143-152. doi:10.1007/s00294-008-0206-X

Lee SC, Idnurm A (2017) Fungal Sex: The Mucoromycota. Microbiol Spectr 5. doi:10.1128/microbiolspec.FUNK0041-2017

Liu Y, He Q, Cheng P (2003) Photoreception in Neurospora: a tale of two White Collar proteins. Cell Mol Life Sci 60:2131-2138. doi:10.1007/s00018-003-3109-5

Lopez-Nieto MJ et al. (2004) Biotechnological lycopene production by mated fermentation of Blakeslea trispora. Appl Microbiol Biotechnol 66:153-159. doi:10.1007/s00253-004-1669-4

Lorca-Pascual JM, Murcia-Flores L, Garre V, Torres-Martinez S, Ruiz-Vazquez RM (2004) The RING-finger domain of the fungal repressor CrgA is essential for accurate light regulation of carotenogenesis. Mol Microbiol 52:14631474. doi:10.1111/j.1365-2958.2004.04070.x

Luo W et al. (2020) A Negative Regulator of Carotenogenesis in Blakeslea trispora. Appl Environ Microbiol 86. doi:10.1128/AEM.02462-19

Modi SRaVV (1977) Carotenogenesis: Possible mechanism of action of trisporic acid in Blakeslea trispora. Cellular and Molecular Life Sciences 33:31-33

Morreale FE, Walden H (2016) Types of Ubiquitin Ligases. Cell 165:248-248 e241. doi:10.1016/j.cell.2016.03.003 
Mussagy CU, Khan S, Kot AM (2021) Current developments on the application of microbial carotenoids as an alternative to synthetic pigments. Crit Rev Food Sci Nutr:1-15. doi:10.1080/10408398.2021.1908222

Nagy G, Szebenyi C, Csernetics A, Vaz AG, Toth EJ, Vagvolgyi C, Papp T (2017) Development of a plasmid free CRISPR-Cas9 system for the genetic modification of Mucor circinelloides. Sci Rep 7:16800. doi:10.1038/s41598017-17118-2

Navarro E, Penaranda A, Hansberg W, Torres-Martinez S, Garre V (2013) A white collar 1-like protein mediates opposite regulatory functions in Mucor circinelloides. Fungal Genet Biol 52:42-52. doi:10.1016/j.fgb.2012.12.003

Podolec R, Ulm R (2018) Photoreceptor-mediated regulation of the COP1/SPA E3 ubiquitin ligase. Curr Opin Plant Biol 45:18-25. doi:10.1016/j.pbi.2018.04.018

Polaino S et al. (2017) A Ras GTPase associated protein is involved in the phototropic and circadian photobiology responses in fungi. Sci Rep 7:44790. doi:10.1038/srep44790

Ponnu J (2020) Molecular mechanisms suppressing COP1/SPA E3 ubiquitin ligase activity in blue light. Physiol Plant 169:418-429. doi:10.1111/ppl.13103

Purschwitz J et al. (2008) Functional and physical interaction of blue- and red-light sensors in Aspergillus nidulans. Curr Biol 18:255-259. doi:10.1016/j.cub.2008.01.061

Quiles-Rosillo MD, Ruiz-Vazquez RM, Torres-Martinez S, Garre V (2005) Light induction of the carotenoid biosynthesis pathway in Blakeslea trispora. Fungal Genet Biol 42:141-153. doi:10.1016/j.fgb.2004.10.008

Rodriguez-Saiz M, Paz B, De La Fuente JL, Lopez-Nieto MJ, Cabri W, Barredo JL (2004) Blakeslea trispora genes for carotene biosynthesis. Appl Environ Microbiol 70:5589-5594. doi:10.1128/AEM.70.9.5589-5594.2004

Ruiz-Roldan MC, Garre V, Guarro J, Marine M, Roncero MI (2008) Role of the white collar 1 photoreceptor in carotenogenesis, UV resistance, hydrophobicity, and virulence of Fusarium oxysporum. Eukaryot Cell 7:12271230. doi:10.1128/EC.00072-08

Sanz C, Rodriguez-Romero J, Idnurm A, Christie JM, Heitman J, Corrochano LM, Eslava AP (2009) Phycomyces MADB interacts with MADA to form the primary photoreceptor complex for fungal phototropism. Proc Natl Acad Sci U S A 106:7095-7100. doi:10.1073/pnas.0900879106

Sarikaya Bayram $O$ et al. (2010) LaeA control of velvet family regulatory proteins for light-dependent development and fungal cell-type specificity. PLoS Genet 6:e1001226. doi:10.1371/journal.pgen.1001226

Schmidt AD, Heinekamp T, Matuschek M, Liebmann B, Bollschweiler C, Brakhage AA (2005) Analysis of matingdependent transcription of Blakeslea trispora carotenoid biosynthesis genes carB and carRA by quantitative realtime PCR. Appl Microbiol Biotechnol 67:549-555. doi:10.1007/s00253-005-1941-2

Shakya VPS, Idnurm A (2017) The inhibition of mating in Phycomyces blakesleeanus by light is dependent on the MadA-MadB complex that acts in a sex-specific manner. Fungal Genet Biol 101:20-30.

doi:10.1016/j.fgb.2017.02.005 
Silva F, Navarro E, Penaranda A, Murcia-Flores L, Torres-Martinez S, Garre V (2008) A RING-finger protein regulates carotenogenesis via proteolysis-independent ubiquitylation of a white collar-1-like activator. Mol Microbiol 70:1026-1036. doi:10.1111/j.1365-2958.2008.06470.x

Silva F, Torres-Martinez S, Garre V (2006) Distinct white collar-1 genes control specific light responses in Mucor circinelloides. Mol Microbiol 61:1023-1037. doi:10.1111/j.1365-2958.2006.05291.x

Smith KM et al. (2010) Transcription factors in light and circadian clock signaling networks revealed by genomewide mapping of direct targets for Neurospora white collar complex. Eukaryot Cell 9:1549-1556. doi:10.1128/EC.00154-10

Tagua VG, Navarro E, Gutierrez G, Garre V, Corrochano LM (2020) Light regulates a Phycomyces blakesleeanus gene family similar to the carotenogenic repressor gene of Mucor circinelloides. Fungal Biol 124:338-351. doi:10.1016/j.funbio.2019.10.007

Tagua VG et al. (2015) Fungal cryptochrome with DNA repair activity reveals an early stage in cryptochrome evolution. Proc Natl Acad Sci U S A 112:15130-15135. doi:10.1073/pnas.1514637112

Wang B, Zhou X, Loros JJ, Dunlap JC (2015) Alternative Use of DNA Binding Domains by the Neurospora White Collar Complex Dictates Circadian Regulation and Light Responses. Mol Cell Biol 36:781-793.

doi:10.1128/MCB.00841-15

Wang Z, Wang J, Li N, Li J, Trail F, Dunlap JC, Townsend JP (2018) Light sensing by opsins and fungal ecology: NOP-1 modulates entry into sexual reproduction in response to environmental cues. Mol Ecol 27:216-232. doi: $10.1111 / \mathrm{mec} .14425$

Yang T, Guo M, Yang H, Guo S, Dong C (2016) The blue-light receptor CmWC-1 mediates fruit body development and secondary metabolism in Cordyceps militaris. Appl Microbiol Biotechnol 100:743-755. doi:10.1007/s00253015-7047-6

Zoltowski BD, Imaizumi T (2014) Structure and Function of the ZTL/FKF1/LKP2 Group Proteins in Arabidopsis. Enzymes 35:213-239. doi:10.1016/B978-0-12-801922-1.00009-9

\section{Figures}


a
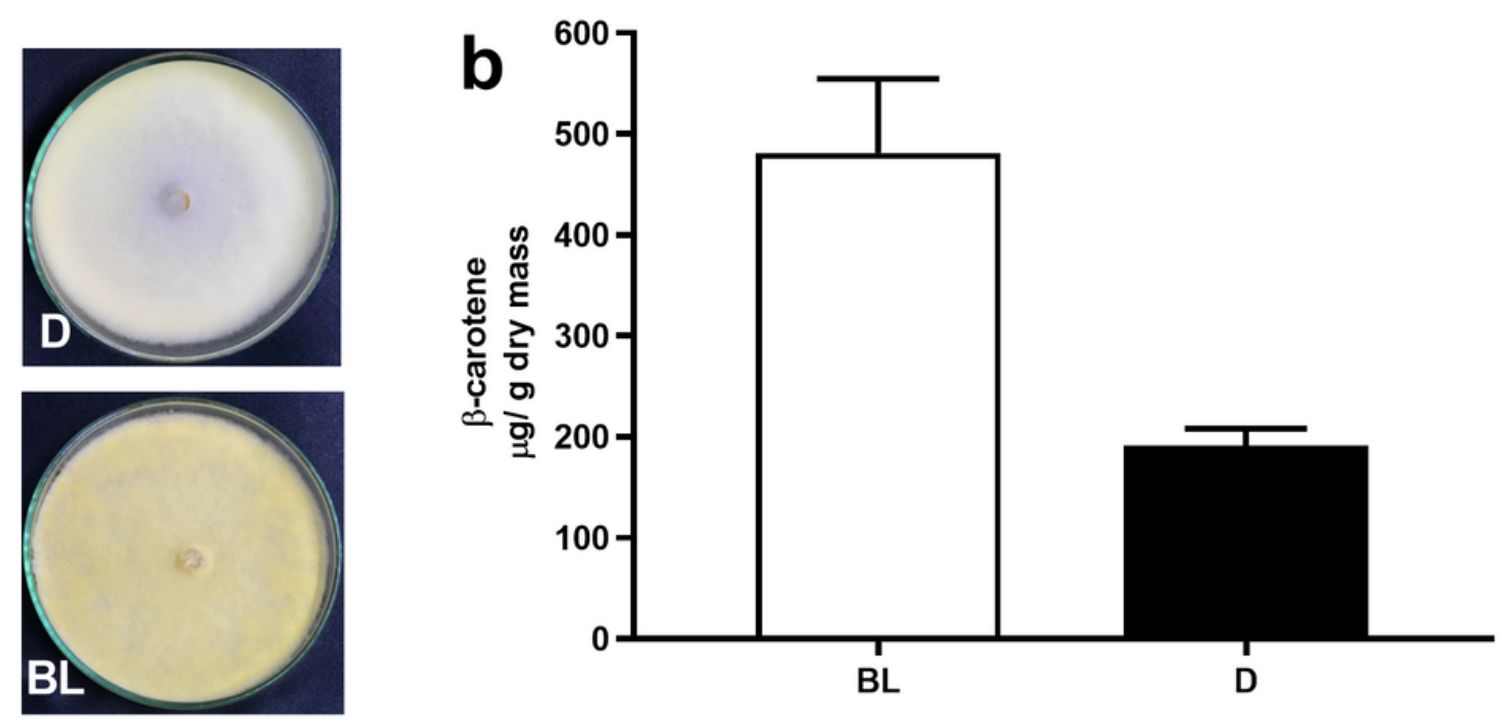

C

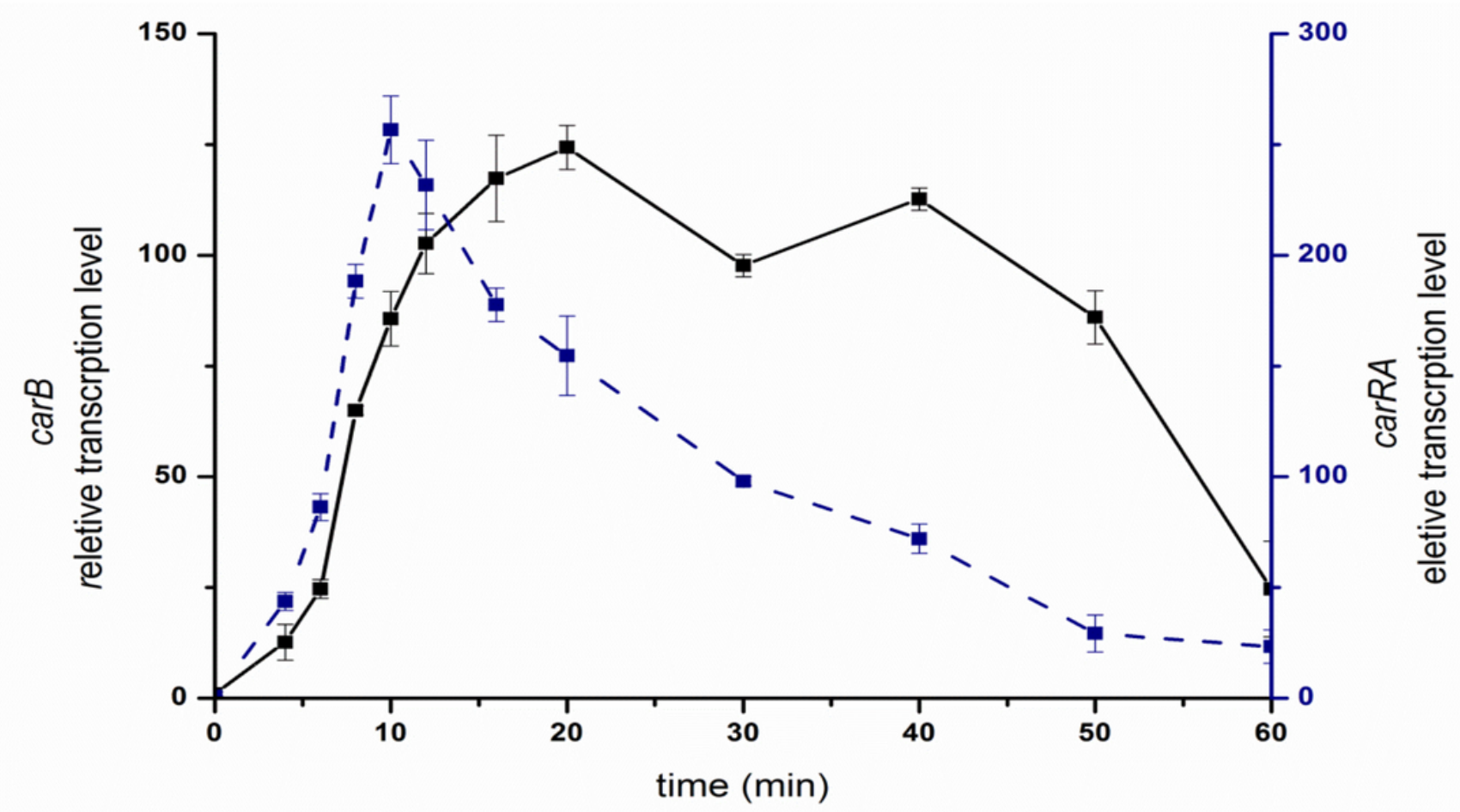

Figure 1

Light-induced accumulation of $\beta$-carotene contents and carotenogenic gene transcripts in B. trispore. Mycelia of the B. trispora grown for $60 \mathrm{~h}$ in minimal medium in the dark were illuminated with blue light for $24 \mathrm{~h}$. (a) The phenotypes and (b) $\beta$-carotene contents in 24-hour-old cultures under blue light were dedicated. The symbol "BL" indicates cultures illuminated by blue light while the controls " $D$ " were kept in the dark. (c) Time course curves of relative transcription levels for carRA (blue) and carB (black) in B. trispore. Data are the means of three independent experiments. 
a

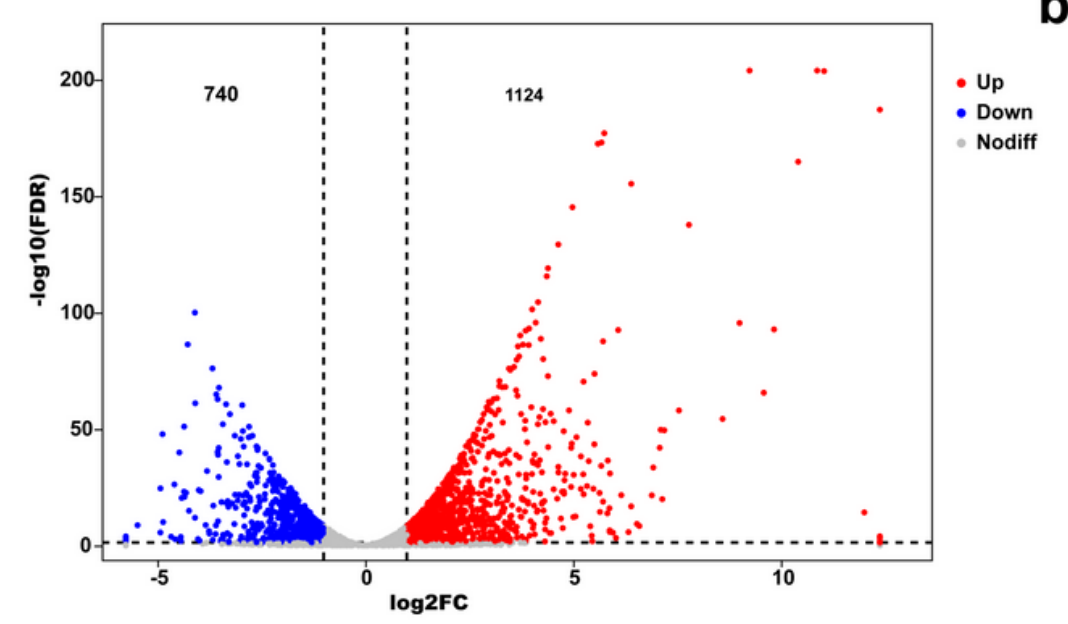

b

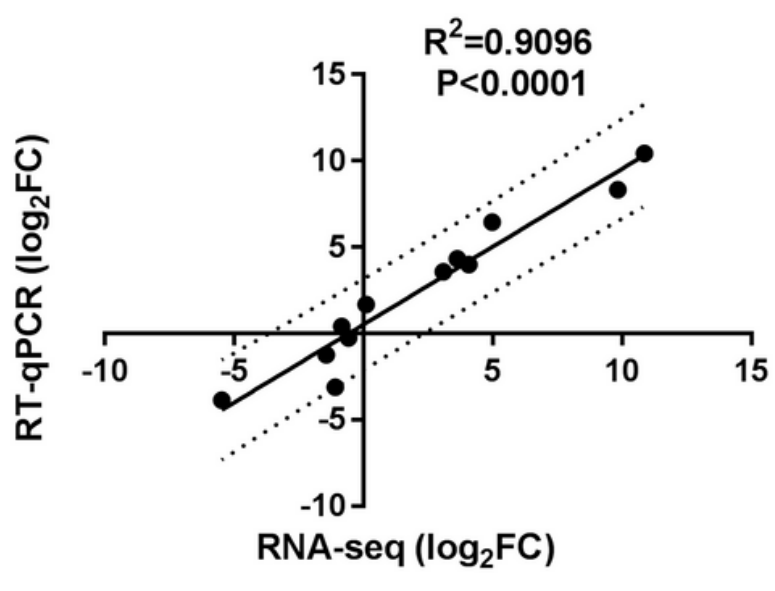

Figure 2

(a) Volcano plot representations of global expression data of the B. trispora genes after blue light exposure. (b) Correlation between RNAseq and quantitative real-time PCR (RT-qPCR). Comparison between the Log2 fold change values obtained by RNA-seq and qRT-PCR for carRA, carB and ten other randomly selected genes, showing a high correlation between the two techniques $(R 2=0.9096)$. 
a

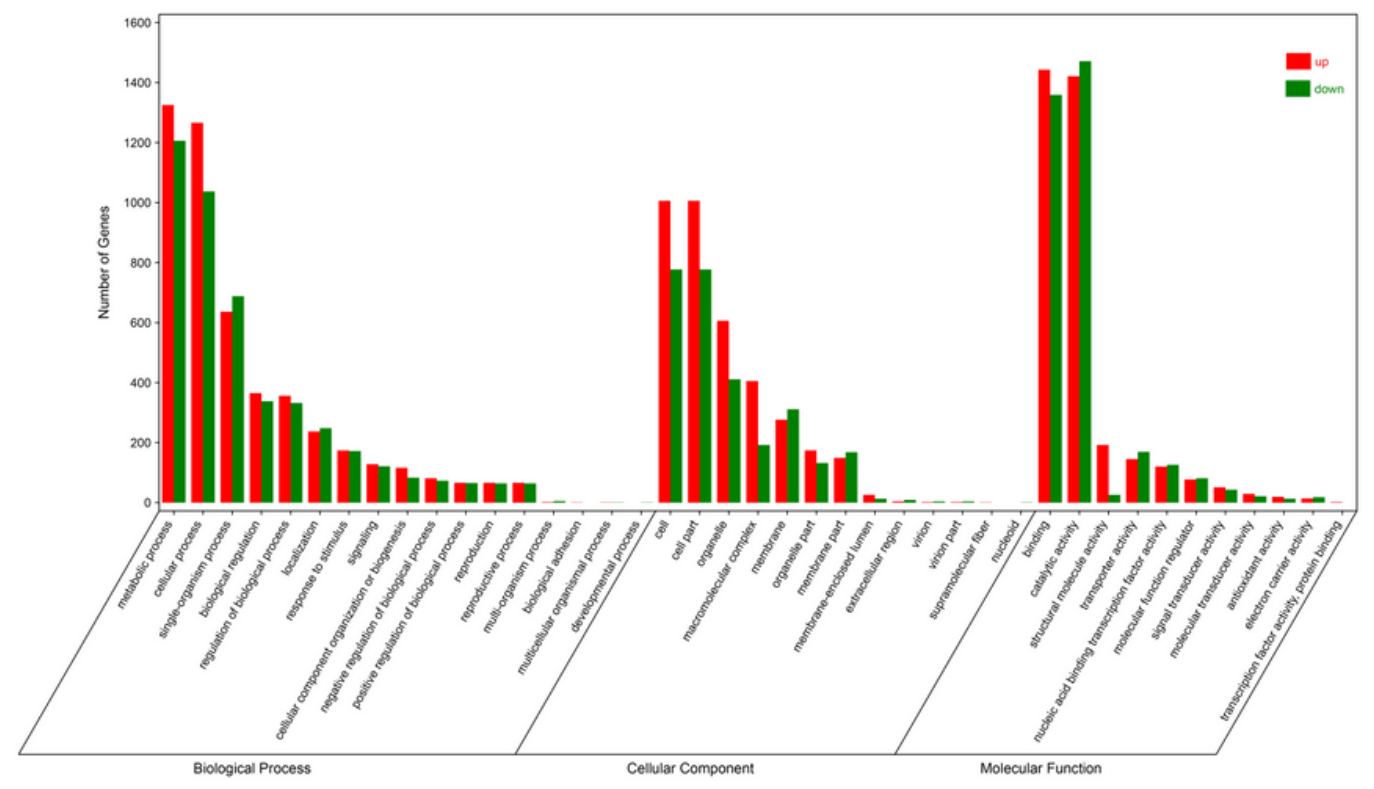

b

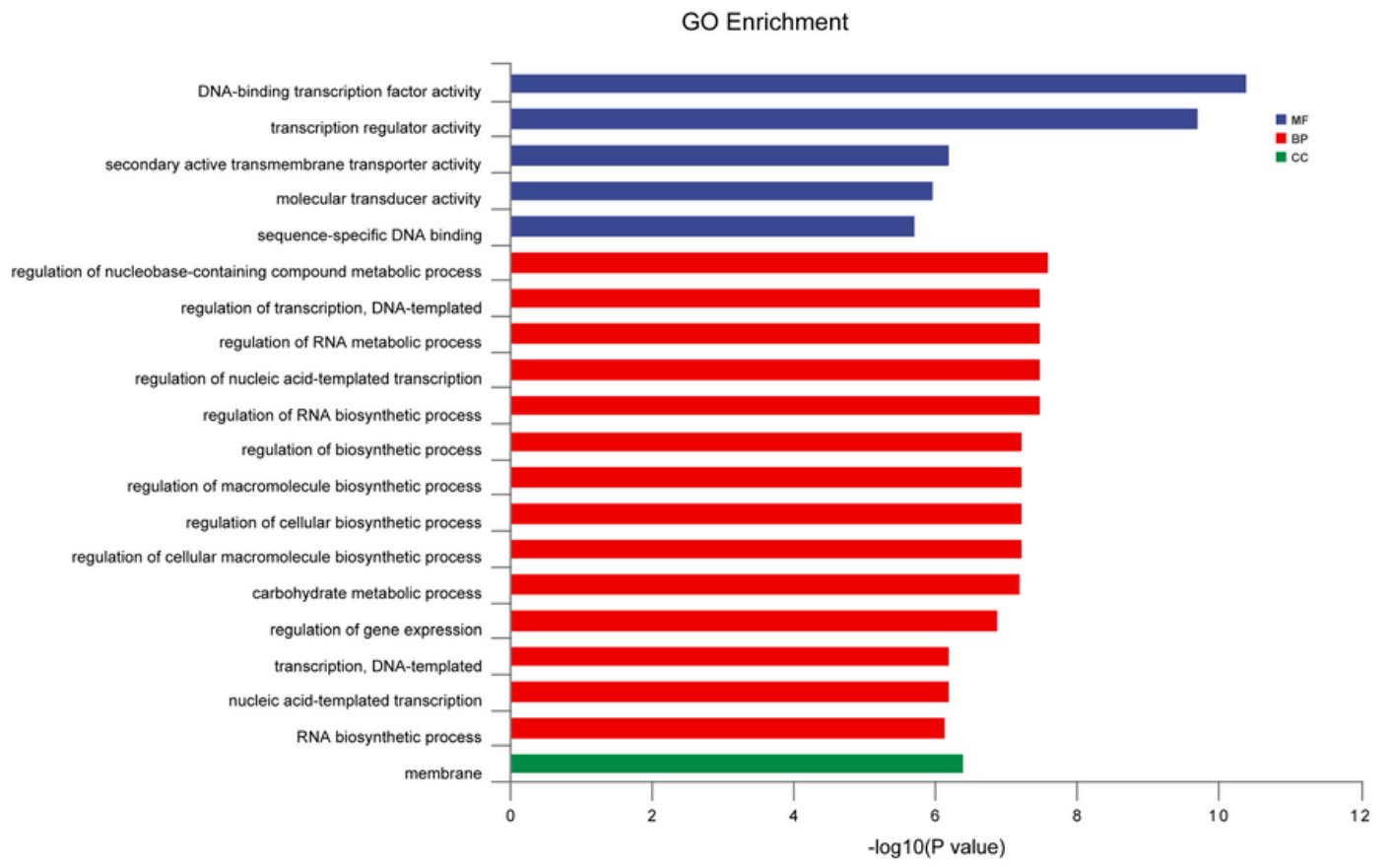

Figure 3

The GO-term analysis of DEGs. A. These DEGs were classified into three main categories including cellular component, biological process and molecular function. B. the most 20 enriched GO subcategories. 
KEGG Enrichment

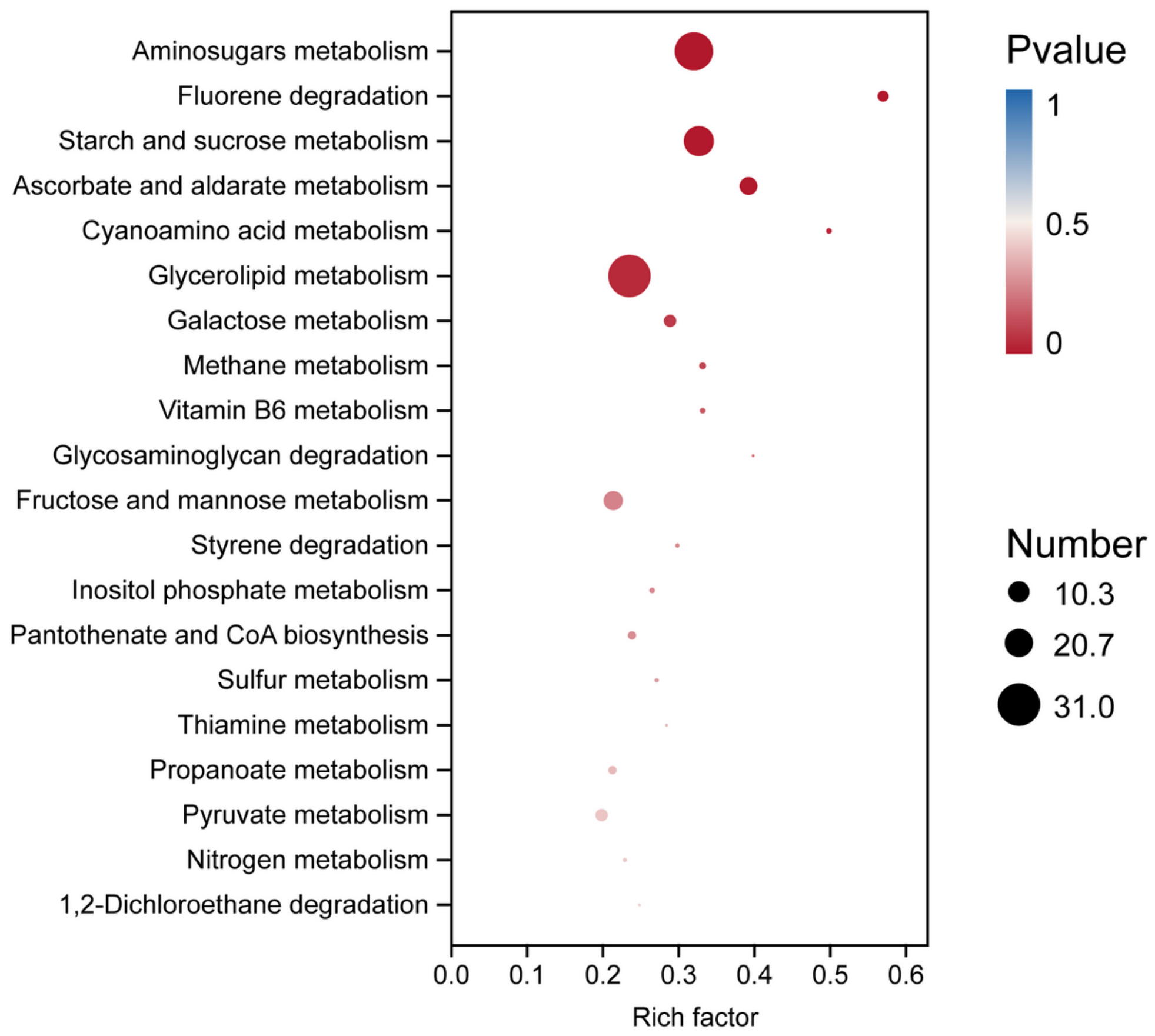

Figure 4

Top 20 KEGG pathways with the most significant enrichment correlated with blue light exposure. 
a

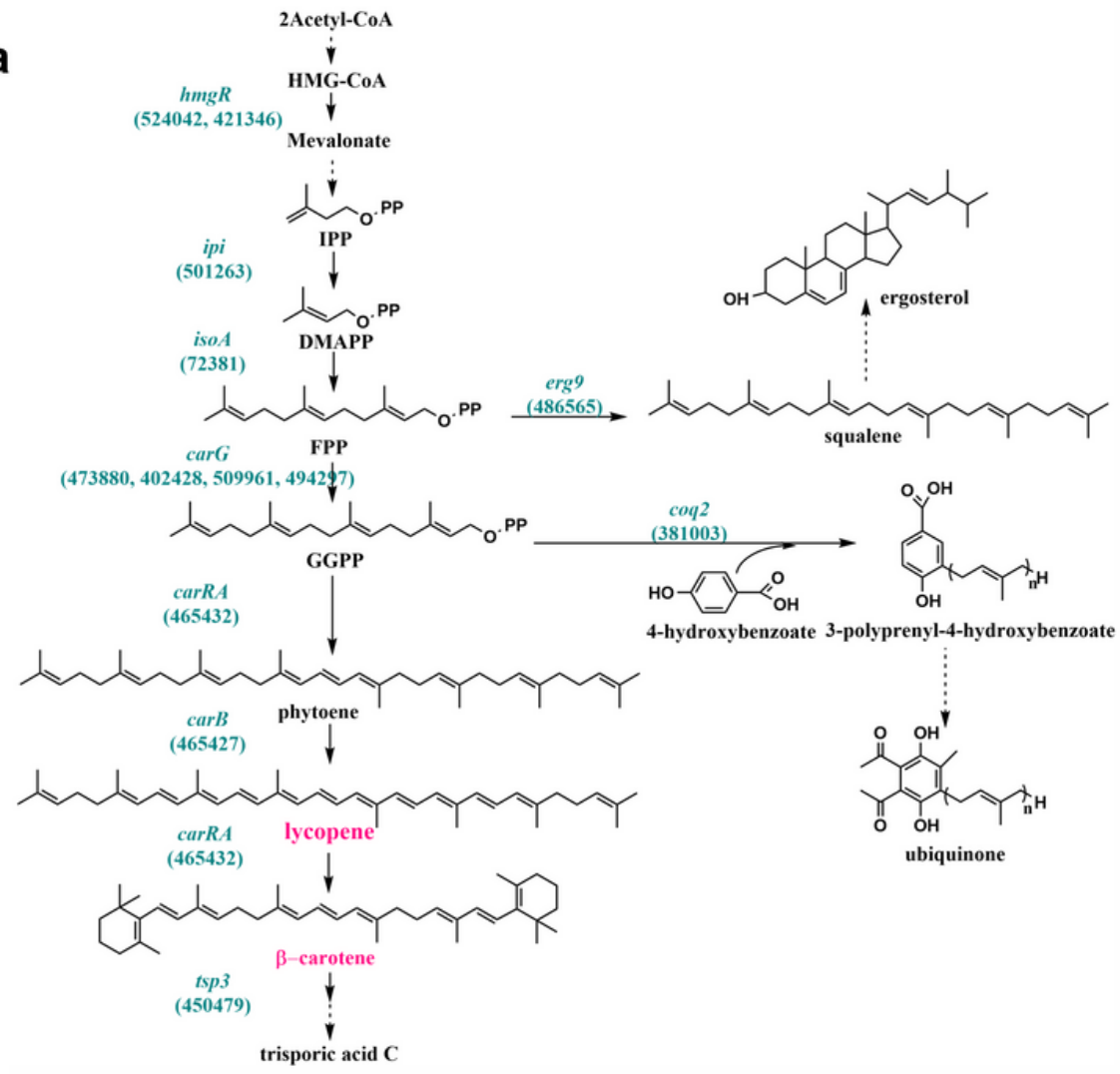

b

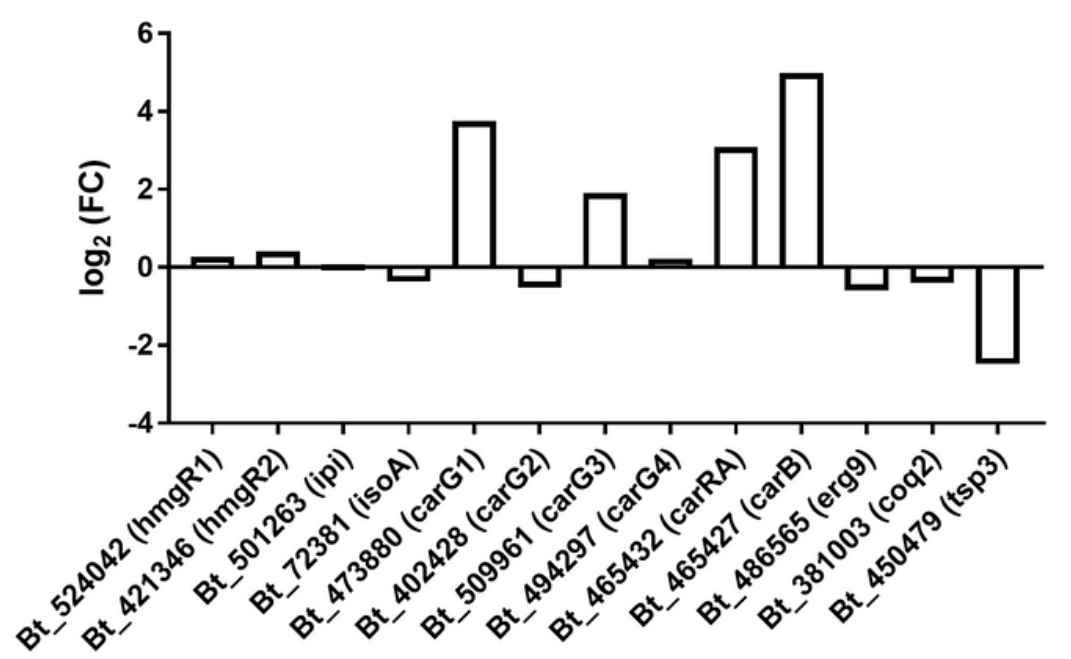

Figure 5

(a) Schematic diagram of the biosynthetic pathway and the branched metabolic pathway and genes encoding respective proteins involved in $\beta$-carotene metabolism. (b) The transcript levels of the related genes in (a) obtained from transcriptome data.

\section{Supplementary Files}

This is a list of supplementary files associated with this preprint. Click to download. 
- SupplementaryInformation.docx

Page 23/23 